\title{
Cardiac Stent Placement
}

National Cancer Institute

\section{Source}

National Cancer Institute. Cardiac Stent Placement. NCI Thesaurus. Code C100080.

A procedure performed during a percutaneous coronary intervention in which a device is deployed into the lumen of a coronary artery to expand and support the vessel wall such that the vessel remains patent and blood flow is uninhibited. 